\title{
Sleep-related hypoxaemia and excessive erythrocytosis in Andean high-altitude natives
}

\author{
L. Spicuzza*, N. Casiraghi”, A. Gamboa , C. Keyl ${ }^{+}$, A. Schneider ${ }^{+}$, A. Mori ${ }^{\S}$, F. Leon-Velarde ${ }^{\Uparrow}$, \\ G.U. Di Maria*, L. Bernardi
}

Sleep-related hypoxaemia and excessive erythrocytosis in Andean high-altitude natives. L. Spicuzza, N. Casiraghi, A. Gamboa, C. Keyl, A. Schneider, A. Mori, F. Leon-Velarde, G. U. Di Maria, L. Bernardi. (C) ERS Journals Ltd 2004.

ABSTRACT: To determine whether nocturnal hypoxaemia contributes to the excessive erythrocytosis (EE) in Andean natives, standard polysomnographies were performed in 10 patients with $E E$ and in 10 controls (mean haematocrit $76.6 \pm 1.3 \%$ and $54.4 \pm 0.8 \%$, respectively) living at an altitude of $4,380 \mathrm{~m}$. In addition, the effect of $\mathrm{O}_{2}$ administration for $1 \mathrm{~h}$ prior to sleep, and the relationship between the hypoxicl hypercapnic ventilatory response and the apnoea/hypopnoea index (AHI) during sleep were studied.

Awake arterial oxygen saturation $\left(S_{\mathrm{a}}, \mathrm{O}_{2}\right)$ was significantly lower in patients with EE than in controls $(83.7 \pm 0.3 \%$ versus $85.6 \pm 0.4 \%)$. In both groups, the mean $\mathrm{S}_{\mathrm{a}}, \mathrm{O}_{2}$ significantly decreased during sleep (to $80.0 \pm 0.8 \%$ in $\mathrm{EE}$ and to $82.8 \pm 0.5 \%$ in controls). The mean $S_{a}, O_{2}$ values remained significantly lower in patients with $E E$ than in controls at all times of the night, and patients with $\mathrm{EE}$ spent significantly more time than the controls with an $\mathrm{Sa}_{\mathrm{a}} \mathrm{O}_{2}$ of $<80 \%$. There were no differences between the two groups in the number and duration of the apnoeas/hypopnoeas. None of these variables were affected by $\mathrm{O}_{2}$ administration. In both groups the AHI positively correlated with the hypercapnic ventilatory response.

Andean natives undergo minor respiratory disorders during sleep. The reduction in oxygen saturation found in subjects with excessive erythrocytosis was small, yet consistent and potentially important, as it remained below the threshold known for the increase in erythropoietin stimulation. This may be an important factor promoting erythropoiesis, but its relevance needs to be further explored.

Eur Respir J 2004; 23: 41-46.
*Dept of Internal Medicine and Medical Specialities, University of Catania, "Dept of Internal Medicine and ${ }^{\S}$ Pathology, IRCCS S. Matteo and University of Pavia, Italy. "University Cayetano Heredia, Lima, Peru. ${ }^{+}$Dept of Anaesthesiology, University of Regensburg, Germany.

Correspondence: L. Spicuzza

Dept of Internal Medicine and Medical Specialities University of Catania

Catania

Italy

Fax: 390957594532

E-mail: luciaspicuzza@tiscalinet.it

Keywords: Autonomic nervous system chronic mountain sickness

erythropoietin

high altitude

polycythaemia

sleep disturbances

Received: January 32003

Accepted after revision: August 212003
Excessive erythrocytosis (EE) and hypoxaemia are the major features of a syndrome known as "chronic mountain sickness" (CMS) [1,2] affecting millions of highlanders around the world and particularly common among Andean natives. The pathogenesis of EE is still unclear. In fact, while the increased erythropoiesis in highlanders is considered a mechanism of adaptation to the hypoxic environment, it is not clear why some of these subjects develop EE. One possible explanation is that a blunted hypoxic ventilatory response observed in highlanders with EE may induce a chronic hypoventilation that worsens the hypoxaemia [3]. Other authors have suggested that sleep-related hypoxaemia may be the cause of EE [2,4]. This suggestion is based on the observation that hypoventilation is a physiological feature of the sleep state at sea-level as well [5]. In addition, substantial nocturnal hypoxaemia has been reported in highlanders at $3,100 \mathrm{~m}$ and $3,658 \mathrm{~m}[6,7]$ and sleep-disordered breathing (SDB) is a common finding in lowlanders ascending to high altitude [8-10]. CoOTE and co-workers [11, 12] were the first to perform sleep studies in healthy Andean natives above $4,000 \mathrm{~m}$ and to determine the presence of nocturnal periodic breathing associated with a moderate fall in arterial oxygen saturation $\left(\mathrm{Sa}, \mathrm{O}_{2}\right)$. This finding led these authors to emphasise the importance of studying the nocturnal respiratory pattern in detail in these subjects. This should allow definitive conclusions to be drawn about the importance of nocturnal hypoventilation and/or SDB in the development of polycythaemia. However, to date, a comparison of the nocturnal respiratory profile between Andean highlanders with and without $\mathrm{EE}$ has never been performed.

Therefore, the frequency and duration of nocturnal apnoea/ hypopnoea episodes, oxygen saturation, and sleep parameters in a group of patients with EE were compared with a group of controls that were permanent residents in the Andean town of Cerro de Pasco (Peru) at an altitude of 4,380 m.

The occurrence of SDB at altitude could be related to an altered hypoxic and/or hypercapnic ventilatory response [10, $13,14]$. However, the ventilatory control of lowlanders during acute exposure to altitude is markedly different from that found in altitude natives $[3,15]$. Therefore, in order to investigate a possible correlation between the hypoxic/hypercapnic ventilatory response and the presence of SDB in the subjects, the ventilatory response to isocapnic hypoxia and to normoxic hypercapnia was assessed by classic rebreathing manoeuvres.

Finally, in a preliminary report, it was suggested, at least during wakefulness, that the depressed ventilation described in patients with EE may be reversed by the acute $(1 \mathrm{~h})$ administration of $\mathrm{O}_{2}$ [15]; similarly, a recent study showed an increase in ventilation during $\mathrm{O}_{2}$ administration in similar patients [16]. These previous references thus provided a rationale for testing whether the $1-\mathrm{h}$ administration of $\mathrm{O}_{2}$ 
prior to sleep could improve oxygen saturation (and consequently sleep parameters) during the night.

\section{Methods}

\section{Subjects}

The experiments were conducted in the Andean town of Cerro de Pasco, Peru, at an altitude of 4,380 m, during September 1-28, 2001. Two groups (EE and controls) of 10 subjects were selected for this study, on the basis of their haematocrit $(\mathrm{Ht})$ and haemoglobin $(\mathrm{Hb})$. The values for establishing the presence of EE were chosen according to studies from LEON-VELARDE and co-workers [17, 18] who measured $\mathrm{Hb}$ in the population of Cerro de Pasco and found a 95 percentile of $21.3 \mathrm{~g} \cdot \mathrm{dL}^{-1}$, which corresponds to a $\mathrm{Ht}$ of $\sim 64 \%$. The SD of $\mathrm{Ht}$ and $\mathrm{Hb}$ in the healthy middle-aged male population in Cerro de Pasco is $3.13 \%$ and $1.21 \mathrm{~g} \cdot \mathrm{dL}^{-1}$, respectively [19]. Therefore, the EE group was comprised of those subjects with an $\mathrm{Ht}$ of $\geqslant 70 \%$ and $\mathrm{Hb}$ of $\geqslant 22.5 \mathrm{mg} \cdot \mathrm{dL}^{-1}$, and the control group of subjects with an $\mathrm{Ht} \leqslant 60 \%$ and $\mathrm{Hb} \leqslant 19.5 \mathrm{mg} \cdot \mathrm{dL}^{-1}$. Two groups of 10 subjects were established with these characteristics and provided a chance of $\geqslant 99 \%$ for detecting significant differences in these variables. All the subjects were selected from the male population of Cerro de Pasco among those who fulfilled these criteria. All subjects were Mestizos who were born and had lived their life at that altitude (no visit to a lower altitude in the last 12 months) and none of them was employed as a miner. The characteristics of the subjects are shown in table 1. Lung function was assessed by performing a standard flow/ volume spirometric curve with a Microlab 3500 (Sensormedics, Milan, Italy). The calibration of the pneumotachygraph was checked by a known air volume by a calibrated syringe. The CMS score was assessed by a previously described [17] questionnaire on clinical symptoms and signs (table 1).

\section{Study protocol and polysomnography}

All subjects underwent two consecutive nights of standard polysomnography in Cerro de Pasco, in the "Laboratorio del Instituto de Investigaciones de la Altura" of the Universidad Peruana Cayetano Heredia of Lima, Peru. In the first night of the study, the polysomnography was performed under basal conditions while in the second night $\mathrm{O}_{2}$ was administered by a facial mask for $1 \mathrm{~h}$ prior to sleep. For each patient the $\mathrm{O}_{2}$ flow was regulated in order to maintain $\mathrm{Sa}, \mathrm{O}_{2}$ above sea-level values $(>96 \%)$. Polysomnographic recordings were performed

Table 1.-Demographic, clinical and haematological data of the subjects

\begin{tabular}{lccc}
\hline & EE & Controls & p-value \\
\hline Age yrs & $38.9 \pm 2.5$ & $38.5 \pm 1.4$ & $\mathrm{NS}$ \\
BMI kg $\cdot \mathrm{m}^{-2}$ & $23.3 \pm 0.2$ & $23.4 \pm 0.8$ & $\mathrm{NS}$ \\
Haematocrit \% & $76.6 \pm 1.3$ & $54.4 \pm 0.8$ & $<0.0001$ \\
Haemoglobin $\mathrm{g} \cdot \mathrm{dL}^{-1}$ & $23.5 \pm 0.3$ & $16.9 \pm 1.0$ & $<0.0001$ \\
Red blood cells $\times 10^{9} \cdot \mathrm{L}^{-1}$ & $7.4 \pm 0.1$ & $5.5 \pm 0.1$ & $<0.0001$ \\
CMS score & $23.8 \pm 3.3$ & $10.3 \pm 3.2$ & $<0.0001$ \\
FVC L & $4.43 \pm 0.80$ & $4.55 \pm 0.54$ & $\mathrm{NS}$ \\
FEV1 L & $3.52 \pm 0.65$ & $3.80 \pm 0.44$ & $\mathrm{NS}$ \\
\hline
\end{tabular}

Data are presented as mean \pm SEM unless otherwise stated; BMI: body mass index; CMS: chronic mountain sickness; FVC: forced vital capacity; FEV1: forced expiratory volume in one second; NS: nonsignificant. using a Compumedics P-Series, 18-channel sleep recorder (Abbotsford, Victoria, Australia) with a standard set-up according to the American Sleep Disorders Association [20]. Sleep stages were identified by electroencephalogram (EEG; $\mathrm{C} 3 / \mathrm{A} 2$ and C4/A1), electro-oculogram and by a bipolar submental electromyogram (EMG); all recordings were obtained from surface electrodes. Thoracic and abdominal excursions were detected by inductance plethysmographic bands. Airflow was detected by a nasal-oral thermocouple and $\mathrm{Sa}, \mathrm{O}_{2}$ by a finger pulse oximeter. The electrocardiogram was monitored from precordial leads. Sleep stages were scored according to RECHTSCHAFFEN and KALES [21]. Sleep efficiency was defined as the total sleep time (TST) divided by total registration time. Arousals were defined as an EEG shift in the $\alpha$ or $\theta$ frequency having a duration of $>3 \mathrm{~s}$ associated with an increase in chin EMG [22]. Arousal index was defined as the number of arousals $\cdot h$ sleep ${ }^{-1}$. Apnoeas and hypopnoeas were defined as a complete cessation or a $>50 \%$ decrease in airflow, respectively, for $\geqslant 10 \mathrm{~s}$, associated with a decrease in $\mathrm{Sa}, \mathrm{O}_{2}$ of $\geqslant 3 \%$. Obstructive apnoeas were distinguished from central apnoeas by the presence of respiratory effort (thoracicl abdominal excursions). The apnoea/hypopnoea index (AHI) was defined as the number of apnoeas or hypopnoeas per hour of sleep according to standard definitions [20]. The drop in $\mathrm{Sa}, \mathrm{O}_{2}\left(\Delta \mathrm{Sa}, \mathrm{O}_{2}\right)$ during each apnoea/hyperpnoea episode was measured and averaged for the whole study period and is labelled $\mathrm{m} \Delta \mathrm{Sa}, \mathrm{O}_{2}$. The mean $\mathrm{Sa}, \mathrm{O}_{2}$ during 10 min of recording before sleep was defined as "awake $\mathrm{Sa}, \mathrm{O}_{2}$ ". The average of the $\mathrm{Sa}, \mathrm{O}_{2}$ during the whole sleep time is defined as "mean sleep $\mathrm{Sa}, \mathrm{O}_{2} "$.

\section{Hypoxic and hypercapnic ventilatory response}

On the first and second study day, in order to determine the hypoxic (HVR) and the hypercapnic ventilatory response (HCVR), the subjects were studied in the seated position (in the morning at rest for $\geqslant 2 \mathrm{~h}$, and $\geqslant 2 \mathrm{~h}$ after a light breakfast with no tea or coffee), and connected to a rebreathing circuit through a mouthpiece, as previously described [23-25]. To assess the response to progressive hypoxia, end-tidal carbon dioxide $\left(\mathrm{ETCO}_{2}\right)$ was kept constant by passing a portion of the expired air into a scrubbing circuit before returning it to the rebreathing bag. Conversely, when the response to progressive hypercapnia was tested, $\mathrm{O}_{2}$ was continuously supplied to the rebreathing circuit in order to maintain $\mathrm{Sa}_{2} \mathrm{O}_{2}$ at sea-level normoxic levels $(>95 \%)$. The rebreathing tests terminated when $\mathrm{Sa}, \mathrm{O}_{2}$ reached $70 \%$ (hypoxic response) or when $\mathrm{ETCO}_{2}$ reached $7.3 \mathrm{kPa}(55 \mathrm{mmHg}$; hypercapnic response). $\mathrm{ETCO}_{2}$ was continuously monitored by COSMOplus (Novametrix, Wallingford, CT, USA) connected to a mouthpiece, and $\mathrm{Sa}, \mathrm{O}_{2}$ by a 3740 Ohmeda Pulse Oximeter (Ohmeda, Englewood, CO, USA). The COSMOplus was precalibrated against known gas mixtures. The airway flow was continuously measured by a Fleish pneumotachygraph (Metabo Epalinges, Lausanne, Switzerland), connected to a differential pressure transducer (RS part N395-257; RS Components Ltd, Corby, UK) connected in series in the expiratory part of the rebreathing circuit. The calibration of the pneumotachygraph was checked before and after each rebreathing manoeuvre. All signals were acquired on a Macintosh personal computer (G3 model; Apple, Coupertino, CA, USA) at the frequency of 300 per sample channel. The respiratory flow signal was integrated by software, and each breath was identified by an automatic and interactive program. Breathing rate, tidal volume, and minute ventilation $\left(V^{\prime} \mathrm{E}\right)$ relative to each breath were recognised with their corresponding values of $\mathrm{Sa}_{2} \mathrm{O}_{2}$ and $\mathrm{ETCO}_{2}$. The chemoreflex 
sensitivity to hypoxia or hypercapnia was obtained from the slope of the linear regression of $V^{\prime} \mathrm{E}$ versus $\mathrm{Sa}, \mathrm{O} 2$ or $\mathrm{ETCO}_{2}$, respectively [23-25].

\section{Statistical analysis}

Differences between groups were analysed using the unpaired t-test or the Mann-Whitney U-test. Differences between groups and sleep and respiratory variables in the two groups and by effects of $\mathrm{O}_{2}$ administration were also tested by mixed-design analysis of variance. Data are presented as mean \pm SD. Linear regression was used to assess correlations between parameters.

\section{Results}

Demographic characteristics of the subjects with haematological and clinical data are shown in table 1 . No significant difference was observed in the lung function of the two groups (table 1). The mean slopes of the HCVR were similar in EE and controls, whereas the HVR slopes were slightly lower in EE than in controls, but the difference was not significant (HVR $-0.43 \pm 0.07 \mathrm{~L} \cdot \mathrm{min}^{-1} . \% \mathrm{Sa}_{\mathrm{a}} \mathrm{O}_{2}^{-1}$ and $-0.67 \pm$ $0.1 \mathrm{~L} \cdot \mathrm{min}^{-1} \% \% \mathrm{Sa}_{2} \mathrm{O}_{2}{ }^{-1}$ for EE and controls, respectively; HCVR $1.31 \pm 0.16 \mathrm{~L} \cdot \mathrm{min}^{-1} \cdot \mathrm{mmHg} \mathrm{CO}_{2}^{-1}$ and $0.97 \pm 0.1 \mathrm{~L} \cdot \mathrm{min}^{-1} \cdot \mathrm{mmHg}$ $\mathrm{CO}_{2}^{-1}$ for EE and control, respectively).

\section{Sleep variables}

During the first study night no significant differences were observed in the TST, sleep efficiency, stages II, III, IV and rapid eye movement (REM) sleep, and the arousal index between the EE and the controls (table 2). Only stage I of sleep was slightly longer in the controls. The arousal index did not correlate with any of the haematological, clinical, demographic or polysomnographic variables of the subjects. For both groups all sleep variables remained unchanged during the second night of the study, in which $\mathrm{O}_{2}$ was administered for $1 \mathrm{~h}$ before sleep (table 2).

\section{Respiratory variables during wakefulness and sleep}

During wakefulness, patients with EE had a significantly lower $\mathrm{Sa}_{2} \mathrm{O}_{2}$ compared with controls $(83.7 \pm 0.3 \%$ versus $85.6 \pm 0.4 \%, \mathrm{p}<0.01)$. In both groups, the mean values of $\mathrm{Sa}, \mathrm{O}_{2}$ significantly decreased, by a similar small extent during sleep (to $80 \pm 0.8 \%$ in $\mathrm{EE}$ and to $82.8 \pm 0.5 \%$ in controls, $\mathrm{p}<0.05$; fig. 1). At all times of the night, the mean $\mathrm{Sa}_{\mathrm{a}} \mathrm{O}_{2}$ values remained significantly lower in EE than in controls (fig. 1). The percentage of time that the two groups spent at various $\mathrm{Sa}, \mathrm{O}_{2}$ per cent ranges is shown in figure 2 . Although both groups spent $>50 \%$ of the time in the $\mathrm{Sa}, \mathrm{O}_{2}$ range $81-85 \%$, the controls spent more time than EE subjects with an $\mathrm{Sa}, \mathrm{O}_{2}$ of $>80 \%$, whereas EE subjects spent more time than the controls with an $\mathrm{Sa}_{2} \mathrm{O}_{2}$ of $<80 \% \quad(\sim 38 \%$ of the night in the range $76-80 \%$ ). Since the TST was the same for both groups, the same findings would be observed if the data were evaluated in terms of actual time spent at each level of $\mathrm{Sa}, \mathrm{O}_{2}$, rather than in terms of percentage. Overall, the subjects with EE spent $10,343 \pm 1,856 \mathrm{~s}$ (i.e. nearly $3 \mathrm{~h}$ ) between $76-80 \% \quad \mathrm{Sa}, \mathrm{O}_{2}$, whereas the controls spent $3,039 \pm 1,543 \mathrm{~s}$ (only $\sim 50 \mathrm{~min}$ ) in the same $S \mathrm{a}, \mathrm{O}_{2}$ range $(\mathrm{p}<0.01)$.

In both EE and controls, REM sleep was not associated with episodes of marked hypoventilation and the lowest $\mathrm{Sa}, \mathrm{O}_{2}$ levels reached were similar during non-REM and REM sleep (table 3).

Both groups exhibited recurrent episodes of periodic breathing characterised mainly by hypopnoeas alternated with hyperpnoeas (fig. 3), while frank central apnoeas were more rare. In only one patient with EE obstructive apnoeas were present. The values of AHI, duration of hypopneas and $\mathrm{m} \Delta \mathrm{Sa}, \mathrm{O}_{2}$ were similar in the two groups (table 3 ). With an AHI of $\sim 10$, the severity of the sleep disorder could be defined as "mild", according to the standard criteria for sea level [26]. The AHI showed a fair correlation with subjects' age $\left(\mathrm{r}^{2}=0.22\right.$, $\mathrm{p}<0.05)$ and, more consistently, with the slope of HCVR $\left(r^{2}=0.59, p<0.05\right)$ but not with the slope of HVR. Administration of $\mathrm{O}_{2}$ prior to sleep in the second night of the study did not alter any of these respiratory parameters (table 3 ).

\section{Discussion}

The new findings of this study are that Andean highaltitude natives, with or without EE, undergo mild respiratory disorders during sleep, and that subjects with EE have a slightly, but highly consistent, lower nocturnal $\mathrm{Sa}_{2} \mathrm{O}_{2}$ and spend significantly more time than controls with an $\mathrm{Sa}_{2} \mathrm{O}_{2}$ of $<80 \%$ during the night. These mild respriatory abnormalities were not affected by 1 -h administration of $\mathrm{O}_{2}$ prior to sleep.

In contrast to the many studies on $\mathrm{SDB}$ in lowlander visitors to altitude, very few studies have addressed the question of breathing during sleep in high-altitude natives, particularly in those with EE. This study clearly indicates that in Andean natives the occurrence of SDB among patients with $\mathrm{EE}$ is similar to high-altitude natives with relatively normal haematocrit in terms of frequency and duration of the periodic breathing. However, although the absolute extent

Table 2. - Sleep variables recorded during the first night (basal) and second night (after oxygen administration) night in excessive erythrocytosis (EE) and in controls

\begin{tabular}{|c|c|c|c|c|}
\hline & Basal EE & After oxygen EE & Basal controls & After oxygen controls \\
\hline TST min & $333 \pm 15$ & $348 \pm 14.5$ & $312 \pm 20.7$ & $335 \pm 13$ \\
\hline Sleep efficiency $\%$ & $79.4 \pm 3.5$ & $83.8 \pm 3.1$ & $74.4 \pm 4.9$ & $81.3 \pm 3.2$ \\
\hline Stage $1(\%$ of TST) & $5.2 \pm 0.7$ & $4.2 \pm 1.3$ & $9.3 \pm 1.4$ & $7.2 \pm 1.6$ \\
\hline Stage $2(\%$ of TST) & $55.6 \pm 4.2$ & $49.6 \pm 5.2$ & $50.9 \pm 3.7$ & $55.4 \pm 3.9$ \\
\hline Stage $3(\%$ of TST) & $25.5 \pm 3.1$ & $26.0 \pm 4.4$ & $17.5 \pm 2.1$ & $18.7 \pm 1.9$ \\
\hline Stage 4 ( $\%$ of TST) & $8.8 \pm 2.1$ & $8.4 \pm 2.0$ & $8.7 \pm 2.4$ & $8.9 \pm 1.7$ \\
\hline REM $(\%$ of TST) & $9.8 \pm 1.9$ & $11.0 \pm 2.9$ & $11.5 \pm 3.6$ & $9.5 \pm 2.6$ \\
\hline REM latency min & $108 \pm 30$ & $102 \pm 43$ & $126 \pm 22$ & $104 \pm 28$ \\
\hline Arousals index & $12.0 \pm 1.8$ & $11.2 \pm 0.8$ & $12.7 \pm 1.3$ & $10.7 \pm 2.1$ \\
\hline
\end{tabular}

Data are presented as mean \pm SEM unless otherwise stated; TST: total sleep time; REM: rapid eye movement; All p-values of EE versus controls, and basal versus after oxygen are nonsignificant. 




Awake 23:00- 00:00- 01:00- 02:00- 03:00- 04:00- 05:00-


Hours of night

Fig. 1.-Time course of the nocturnal arterial oxygen saturation $\left(\mathrm{S}_{\mathrm{a}, \mathrm{O}_{2}}\right)$ in 10 subjects with excessive erythrocytosis $(\mathrm{EE} ;-)$ and in 10 controls $(\bigcirc)$. Values are expressed as mean \pm SEM. The $\mathrm{Sa}_{\mathrm{a}, \mathrm{O}_{2}}$ decreased significantly $(\mathrm{p}<0.01)$ from the awake state throughout the sleep period in both EE and control groups. *: $\mathrm{p}<0.05$ EE versus control; **: $\mathrm{p}<0.01 \mathrm{EE}$ versus control.

of nocturnal desaturation was the same for EE and controls, EE subjects, who had lower $\mathrm{Sa}, \mathrm{O}_{2}$ during the day, maintained a lower $\mathrm{Sa}, \mathrm{O}_{2}$ during the night. This difference was small in absolute terms, but very consistent and prolonged during the entire period of the night, and, in addition, it allowed the EE group to spend a substantial period of the night with an $\mathrm{Sa}, \mathrm{O}_{2}$ of $<80 \%$. Transient oxygen desaturations, even reaching very low values in $S \mathrm{a}, \mathrm{O}_{2}$, are not considered an important stimulus for the production of erythropoietin, whereas clinical conditions such as chronic obstructive pulmonary diseases and chronic respiratory failure, characterised by stable and prolonged hypoxaemia may be associated with polycythaemia [27]. Therefore, it is likely that the percentage of sleep time spent below a specific given level of $\mathrm{Sa}, \mathrm{O}_{2}$ may be a determinant of the haematopoietic response to hypoxia, even in the absence of transient dramatic desaturations.

The authors found that EE patients spent one-half of the night with an $\mathrm{Sa}_{\mathrm{a}} \mathrm{O}_{2}$ in the range of $81-85 \%$, and $38 \%$ of the night in the range of $76-80 \%$, whereas the healthy controls spent most of the time with an $\mathrm{Sa}, \mathrm{O}_{2}$ of $>81 \%$. This points to a possible $\mathrm{Sa}, \mathrm{O}_{2}$ cut-off value of $\sim 80 \%$, below which the haematopoiesis may be stimulated. The presence of a threshold of $80 \% \quad \mathrm{Sa}_{2} \mathrm{O}_{2}$ for the stimulation of erythropoietin

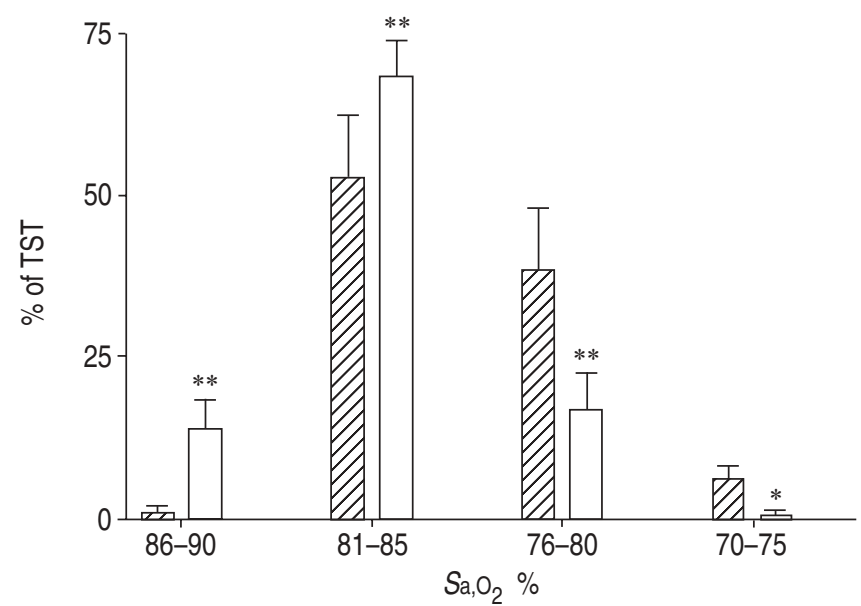

Fig. 2.-Histogram showing the percentage of time spent in different arterial oxygen saturation $\left(\mathrm{Sa}_{\mathrm{a}} \mathrm{O}_{2}\right)$ ranges for excessive erythrocytosis patients $(\mathbb{Z})$ and controls $(\square)$. Groups were compared using a MannWhitney U-test $*$ : $\mathrm{p}<0.05$ versus control; ${ }^{* *}: \mathrm{p}<0.01$ versus control.

has been clearly documented previously [28]. Therefore, it is possible that a mean reduction of $3-4 \%$ in nocturnal $\mathrm{Sa}_{\mathrm{a}} \mathrm{O}_{2}$, which has no effect in normal subjects, may drag patients with $\mathrm{EE}$ that have lower diurnal $\mathrm{Sa}, \mathrm{O}_{2}$ below a value that is critical for erythropoiesis. This exactly crosses the difference between the controls and EE subjects (fig. 1), and may thus explain at least in part why, even in the absence of major respiratory disorders some subjects develop polycythaemia, while others do not, despite intergroup small differences in $\mathrm{Sa}_{2} \mathrm{O}_{2}$. At an altitute of $3,100 \mathrm{~m}$ (Leadville, Colorado) and at $3,658 \mathrm{~m}$ (Lhasa), it has been found that nocturnal hypoxaemia in polycythaemic subjects is more marked compared with the EE group (although polycythaemia is less severe at lower altitude) $[6,7]$. One possible explanation is that there may be differences between ethnic groups. It is also possible that the different altitude at which these studies were performed may have determined these different results. While at lower altitude a more severe SDB is necessary in order to induce excessive polycythaemia, at higher altitude even a mild SDB could induce moderate/severe polycythaemia, whereas a more severe SDB could be incompatible with life.

The finding that SDB, though not severe, occurs in the Andean population at $4,380 \mathrm{~m}$ is per se of interest. In fact periodic breathing was not reported in a small group of Himalayan Sherpas at an altitude of $>5,000 \mathrm{~m}$ [13]. If these differences were confirmed by larger studies on both populations, then nocturnal respiratory instability in the

Table 3.-Respiratory variables recorded during the first night (basal) and second night (after oxygen administration) in excessive erythrocytosis EE and controls

Basal EE After oxygen EE Basal controls After oxygen controls p-value ${ }^{\#}$ p-value

\begin{tabular}{|c|c|c|c|c|c|c|}
\hline Awake VE L $\cdot \min ^{-1}$ & $12.9 \pm 0.5$ & & $12.0 \pm 0.5$ & & NS & \\
\hline Awake $\mathrm{ETCO}_{2} \mathrm{mmHg}$ & $39.9 \pm 1.0$ & & $38.3 \pm 0.9$ & & NS & \\
\hline Awake $\mathrm{Sa}_{\mathrm{a}} \mathrm{O}_{2} \%$ & $83.7 \pm 0.3$ & $96.6 \pm 0.4^{+}$ & $85.6 \pm 0.4$ & $97.1 \pm 0.5^{+}$ & $<0.01$ & $<0.01$ \\
\hline Mean sleep $S_{a}, \mathrm{O}_{2} \%$ & $80.0 \pm 0.8 * * *$ & $80.3 \pm 0.6$ & $82.8 \pm 0.5^{* * *}$ & $83.6 \pm 0.6$ & $<0.05$ & NS \\
\hline Lowest NREM $\mathrm{Sa}_{\mathrm{a}} \mathrm{O}_{2} \%$ & $69.3 \pm 2.7$ & $68.3 \pm 4.1$ & $74.8 \pm 1.0$ & $74.7 \pm 2.1$ & NS & NS \\
\hline Lowest REM $S \mathrm{a}_{1} \mathrm{O}_{2} \%$ & $71 \pm 2.9$ & $71.8 \pm 1.3$ & $78.5 \pm 1.2$ & $78.8 \pm 1.3$ & NS & NS \\
\hline AHI & $10.0 \pm 4.5$ & $13.2 \pm 7.0$ & $8.7 \pm 2.7$ & $7.0 \pm 2.0$ & NS & NS \\
\hline Mean duration of the apnoea /hypopnea s & $24.2 \pm 1.5$ & $19.5 \pm 1.7$ & $20.3 \pm 1.4$ & $20.8 \pm 0.9$ & NS & NS \\
\hline$\Delta S \mathrm{a}, \mathrm{O}_{2} \%$ & $5.4 \pm 0.6$ & $4.5 \pm 0.6$ & $4.6 \pm 0.2$ & $5.0 \pm 0.2$ & NS & NS \\
\hline
\end{tabular}

Data are presented as mean \pm SEM unless otherwise stated; $V^{\prime} \mathrm{E}$ : minute ventilation; $\mathrm{ETCO}_{2}$ : end-tidal carbon dioxide; $\mathrm{Sa}, \mathrm{O}_{2}$ : arterial oxygen

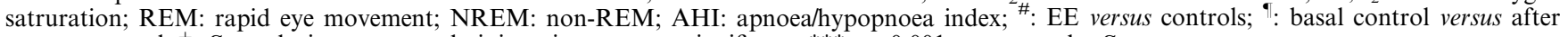
oxygen control; ${ }^{+}: \mathrm{Sa}, \mathrm{O}_{2}$ during oxygen administration; NS: nonsignificant; ***: $\mathrm{p}<0.001$ versus awake $S \mathrm{a}, \mathrm{O}_{2}$. 

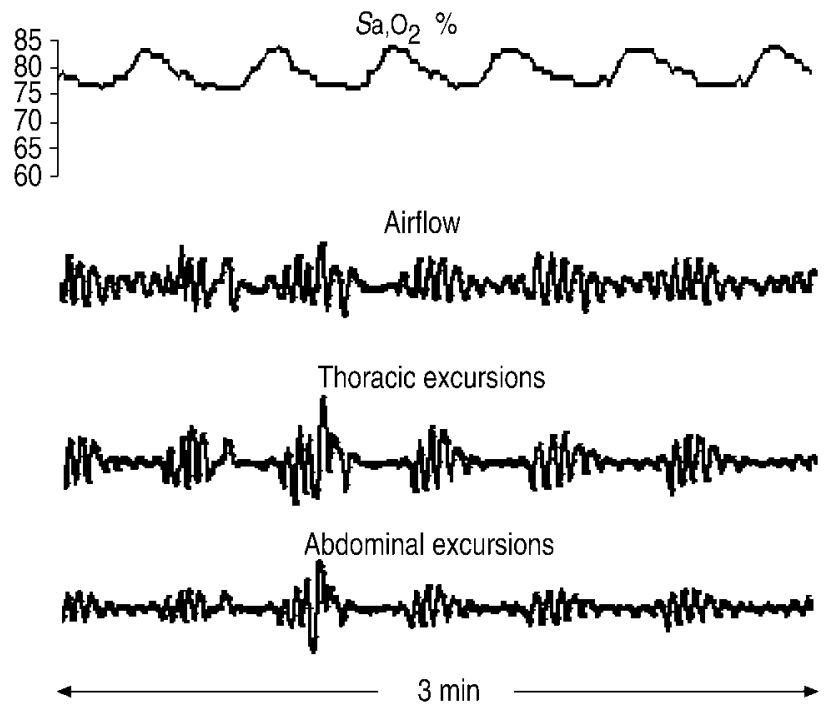

Fig. 3. - Example of periodic breathing from the polysomnographic record of a single patient. $\mathrm{Sa}_{\mathrm{a}, \mathrm{O}_{2}}$ : arterial oxygen saturation.

Andeans may be considered a sign of poor adaptation to altitude.

Both hypoxia and hypocapnia have been suggested as the stimuli that trigger and sustain periodic breathing at altitude $[29,30]$. In sea-level natives ascending to altitude, SDB is related to an increased $\operatorname{HVR}[13,14]$ but in long-term residents at altitude the HVR is blunted [3,31], therefore it is likely that other mechanisms may determine the nocturnal respiratory instability in these subjects. These findings support the hypothesis that the fall in arterial carbon dioxide tension $\left(\mathrm{Pa}, \mathrm{CO}_{2}\right)$ may be a determinant factor. The AHI did not correlate with basal $\mathrm{ETCO}_{2}$, in agreement with a previous report [32] but correlated significantly with the HCVR. Since a fall in $\mathrm{Pa}_{\mathrm{a}} \mathrm{CO}_{2}$ below the apnoeic threshold depends on the individual chemoreflex sensitivity, it is not surprising that the AHI correlated with HCVR rather than with the $\mathrm{ETCO}_{2}$ level itself. The concept that a high gain of central chemoreflex response may lead to nocturnal periodic breathing has been evidenced from many studies in animal and humans [29]. Briefly a low $\mathrm{ETCO}_{2}$ at basal condition may induce hyperventilation with further decrease in $\mathrm{CO}_{2}$ below the apnoeic threshold. The hyperventilation that occurs after each apnoea further decreases the $\mathrm{CO}_{2}$ level triggering the next apnoea and finally leading to a vicious circle. In patients with high hypercapnic chemoreflex sensitivity these responses are enhanced and apnoeas more likely to occur. This mechanism is similar to what is shown at sea level in patients with chronic heart failure experiencing nocturnal (and also diurnal) periodic breathing; in addition, for these patients a clear correlation has been shown between HCVR and SDB [33].

Despite this, a significant difference in HCVR was not found in the two groups, in agreement with a recent study [34], and with the rest of the literature. This suggests that this factor may be able to explain the occurrence of sleep abnormalities (which in fact were present in both EE and controls to a similar extent), as it does in some patients at sea level, but it does not necessarily play a partial role in the origin of EE, whose cause is probably more related to the lower $\mathrm{Sa}, \mathrm{O}_{2}$. The lack of difference in HVR in the two groups could be due to the relatively small number of subjects studied, but again a normal or slightly reduced HVR may not be necessarily the cause of the reduced $\mathrm{Sa}_{\mathrm{a}} \mathrm{O}_{2}$. A depressed HVR is a common finding in Andean natives living at high altitude, regardless of the presence of $\mathrm{EE}[4,16,31]$, and even recent studies confirmed the presence of very small differences between these two groups of subjects [16]. The age of the subjects also has some influence in the occurrence of nocturnal respiratory instability as a slight but significant positive correlation with the AHI was found. There is some evidence that age can be a risk factor for nocturnal periodic breathing also in lowlanders at sea level in the presence of some pathological conditions [35].

All sleep variables were similar in the two groups and this is in agreement with data reported at the same [11, 12] or at a lower altitude [6]. In contrast, lowlanders undergo profound changes in sleep pattern during the first days after ascending to altitude, then improve with acclimatisation $[8,36]$. Taken together these observations suggest that sleep is a physiological variable characterised by a fairly rapid adaptation to the environmental conditions and is not negatively influenced by chronic exposure to altitude.

This study indicates that Andean natives, with or without excessive erythrocytosis, undergo mild respiratory disorders during sleep, and that subjects with excessive erythrocytosis have a slightly (but highly significant) lower nocturnal arterial oxygen saturation and spend more time than controls with an arterial oxygen saturation below $80 \%$ during the night. Since an arterial oxygen saturation of $80 \%$ has been previously identified as a threshold for erythropoiesis, further studies are needed to establish whether or not a link exists between these changes in nocturnal arterial oxygen saturation and excessive erythrocytosis.

\footnotetext{
Acknowledgements. The authors would like to thank J. Milic-Emili, McGill University, Montreal, Canada, for helpful suggestions. They would also like to acknowledge the technical assistance of M. Rosario Tapia Ramirez and J. Antonio Palacios, University Cayetano Heredia, Lima, Peru. They also acknowledge Vivisol SpA (Monza, Italy) and G. Matucci for providing the sleep monitoring systems Compumedics P-Series. Finally, the authors are grateful to M. Piacenti and M. Castiglione (Vivisol Catania, Palermo, Italy) for their technical assistance.
}

\section{References}

1. Monge MC. Sobre un caso de enfermedad de Vaquez. Communicacion presentada a la Academia Nacional de Medicina. [About a case of Vaquez disease. Communication presented to the National Academy of Medicine]. Lima, 1925; pp. 1-6.

2. Monge CC. Chronic mountain sickness: integrative biology. In: Ohno $\mathrm{H}$, Kobayashi $\mathrm{T}$, Masuyama $\mathrm{S}$, eds. Progress in Mountain Medicine and Physiology. Kyoto, Dogura \& Co., 1998; pp. 107-113.

3. Severinghaus JW, Bainton CR, Carcelen A. Respiratory insensitivity to hypoxia in chronically hypoxic man. Respir Physiol 1966; 1: 308-334.

4. Reeves JT, Weil JV. Chronic mountain sickness: a view from the crow's nest. In: Roach RC, Wagner PH, Hackett PH, eds. From Genes to Bedside. New York, Kluwer Academicl Plenum, 2001; pp. 419-437.

5. Gries RE, Brooks LJ. Nocturnal oxyhemoglobin saturation during sleep. Chest 1996; 110: 1489-1492.

6. Kryger M, Glas R, Jackson D, et al. Impaired oxygenation during sleep in polycythemia of high altitude: improvement with respiratory stimulation. Sleep 1978; 1: 3-17.

7. Sun S, Oliver-Pickett C, Ping Y, et al. Breathing and brain blood flow during sleep in patients with chronic mountain sickness. J Appl Physiol 1996; 81: 611-618.

8. Anholm JD, Powels AC, Downey R, et al. Operation Everest 
II: artetial oxygen saturation and sleep at extreme simulated altitude. Am Rev Respir Dis 1992; 145: 817-826.

9. Eichenberger U, Weiss E, Riemann D, Oelz O, Bartsch P. Nocturnal periodic breathing and the development of acute high altitude illness. Am J Respir Crit Care Med 1996; 154: $1748-1754$.

10. Weil JV. Sleep at altitude. Clin Chest Med 1985; 64: 615-621.

11. Coote JH, Stone BM, Tsang G. Sleep of Andean high altitudes natives. Eur J Appl Physiol 1992; 64: 178-181.

12. Coote JH, Tsang G, Baker A, Stone B. Respiratory changes and structure of sleep in young high-altitude dwellers in the Andes of Peru. Eur J Appl Physiol 1993; 66: 249-253.

13. Lahiri S, Maret K, Sherpa MG. Dependence of high altitude sleep apnea on ventilatory sensitivity to hypoxia. Respir Physiol 1983; 52: 281-301.

14. Hackett PH, Roach RC, Harrison GL, et al. Respiratory stimulants and sleep periodic breathing at high altitude: Almitrine vs acetazolamide. Am Rev Respir Dis 1987; 135: 896-898.

15. Bernardi L, Passino C, Gamboa J, et al. Central depression affects ventilatory parameters in high altitude Andean natives with or without polycythemia. High Alt Med Biol 2001; 2: 94

16. Leon-Velarde F, Gamboa A, Rivera-CH M, et al. Plasticity in respiratory motor control: selected contribution. Peripheral chemoreflex function in high-altitude natives and patients with chronic mountian sickness. J Appl Physiol 2003; 94: 1269-1278.

17. Monge $\mathrm{C}$, Leon-Velarde $\mathrm{F}$, Arregui A. Increasing prevalence of excessive erytrocytosis with age among healthy highaltitude miners. N Engl J Med 1989; 321: 1271.

18. Leon-Velarde F, Arregui A, Monge C, Ruiz Y, Ruiz H. Aging at high altitude and the risk of chronic mountain sickness. J Wild Med 1993; 4: 183-188.

19. Leon-Velarde F, Gamboa A, Chuquiza JA, Esteba WA, Rivera-Chira M, Monge CC. Hematological parameters in high altitude residents living at 4355, 4660 and 5500 meters above sea level. High Alt Med Biol 2000; 1: 97-104.

20. American Sleep Disorders Association. Practice parameters for the indications for polysomnography and related procedures. Sleep 1997; 20: 406-422.

21. Rechtschaffen A, Kales A. A manual of standardized terminology techniques and scoring system for sleep stages on human subjects. Washington DC, Public Health service, US Government Printing Office, 1963.

22. American Sleep Disorders Association. EEG Arousals: scoring rules and examples. Sleep 1992; 15: 174-184.
23. Milic-Emili J. Clinical methods for assessing the ventilatory response to carbon dioxide and hypoxia. $N$ Engl J Med 1975; 10: 864-865.

24. Bernardi L, Gabutti A, Porta C, Spicuzza L. Slow breathing reduces chemoreflex response to hypoxia and hypercapnia, and increases baroreflex sensitivity. J Hypertension 2001; 19: 2221-2229.

25. Spicuzza L, Gabutti A, Porta A, Montana N, Bernardi L. Yoga practice decreases chemoreflex response to hypoxia and hypercapnia. Lancet 2000; 356: 1495-1496.

26. Young T, Palta M, Dempsey J, Skatrud J, Weber S, Badr S. The occurrence of sleep disordered breathing among middleaged adults. $N$ Engl J Med 1993; 328: 1230-1235.

27. Seaton A, Seaton D, Leitch AG. Respiratory failure. In: Crofton and Douglas's respiratory diseases. Oxford, Blackwell Scientific Publication, 1989; pp. 526-538.

28. Cohen RA, Miller ME, Garcia JF, Moccia G, Cronkite EP. Regulatory mechanism of erythropoietin production: effects of hypothermia and hypercarbia. Exp Hematol 1981; 9: 513521.

29. Weil JV. Sleep at high altitude. In: Kryger M, Roth T, Dement W, eds. Principle and Practice of Sleep Medicine. Philadelphia, WB Saunders, 1989.

30. Berssenbrugge AD, Dempsey JA, Skatrud JB. Effect of sleep state on ventilatory acclimatization to hypoxia in humans. J Appl Physiol 1984; 57: 1089-1086.

31. Moore LG. Comparative human ventilatory adaptation to high altitude. Respir Physiol 2000; 121: 257-276.

32. White DP, Gleeson K, Pickett CK, Rannels AM, Cymerman A, Weil JV. Altitude acclimatization: influence on ventilatory chemoresponsiveness and periodic breathing during sleep. J Appl Physiol 1987; 63: 401-412.

33. Javaheri S. A mechanism of central sleep apnea in patients with heart failure. $N$ Engl J Med 1999; 341: 985-987.

34. Fatemian M, Gamboa A, Leon-Velarde F, Rivera-CH M, Palacios J, Robbins PA. Plasticity in respiratory motor control selected contribution: ventilatory response to $\mathrm{CO}_{2}$ in high altitude natives and patients with chronic mountain sickness. J Appl Physiol 2003; 94: 1279-1287.

35. Sin DD, Fitzgerald F, Parker JD, Newton G, Floras JS, Bradley TD. Risk factors for central and obstructive sleep apnea in 450 men and women with congestive heart failure. Am J Respir Crit Care Med 1999; 160: 11011106.

36. Zielinski J, Koziej M, Mankowki M, et al. The quality of sleep and periodic breathing in healthy subjects at an altitude of 3200 m. High Alt Med Biol 2000; 1: 331-336. 